\title{
Los ciclos poéticos de Miguel Fernández
}

ANTONIO DOMINGUEZ REY

La mejor introducción a la poética de M. Fernández la encontramos en el poema "Ciclos de la palabra", del último libro publicado en vida, Bóvedas (1992), que fue Premio Nacional de Poesía San Juan de la Cruz, otorgado en Ávila en 1991. Es uno de sus textos más sencillos y claros. Consta de cuatro estrofas. La última recoge y resume los ciclos diseminados alternamente en las otras tres. El primero menciona "lo vivido" y corresponde a la emoción; el segundo, "lo soñado" y su medio es el reino de la música y "el gran tumulto / de las voces", el dictamen irracional, por tanto, de la conciencia en el lenguaje. En el tercer ciclo menciona "lo inventado"y lo describe como "el envés / de lo vivo del sueño", cuya viveza determina otro modo de ver y presentar la realidad. Los tres cierran además sus respectivas estrofas con el gerundio del verbo narrar: "narrando lo vivido", en la primera; "narrando lo soñado", en la segunda; "narrando lo inventado", en la tercera. Esta narración se convierte en cuento al comienzo de la cuarta estrofa, en el primer verso. - "Y cuéntase ya todo"-, mientras que los otros dos compaginan, resumida, la diseminación anterior. El segundo dice: "vivir soñando los inventos", y el tercero precisa la "función vocal" 
del lenguaje. Como cierre, el cuarto verso de esta misma estrofa queda aislado de los demás y sirve de colofón al poema: "Narrando en la palabra" concluye. Dada su importancia, transcribimos el texto para facilitar la comprensión de lo dicho.

\author{
CICLOS DE LA PALABRA \\ "El primero, fue mudo. \\ Tan sólo la emoción, \\ manifestándose. \\ Narrando lo vivido. \\ Y luego el gran tumulto \\ de las voces. \\ La música arpegiando. \\ Narrando lo soñado.
}

Para más tarde andarse en el envés

de lo vivo del sueño.

Así otra realidad.

Narrando lo inventado.

Y cuéntase ya todo:

vivir soñando los inventos

de esa función vocal.

Narrando en la palabra".

De la mudez se pasa al tumulto y de aquí a otro grado de lo real como "envés" de la vivencia onírica. El último verso ofrece además un giro particular con la preposición en, pues el verbo narrar ya implica en su acción, perlocutivamente, el acto que enuncia. Al especificar "en la palabra", la narración aludida adquiere un valor concreto. El cuerpo de la palabra participa en el transcurso narrativo como implicación suya. Además del lugar 
donde acontece, es acontecimiento narrativo. La "función vocal" antes citada encarna la narración misma. El medio no sólo condiciona, también conforma. La función ha convertido al instrumento en parte sustancial del proceso. Esto constituye, como es sabido, un segundo grado de naturaleza verbal, simbólico y metafórico. En él se mueve, efectivamente, casi toda la poesía de M. Fernández.

Advirtamos además que los tres ciclos — vida, sueño, invención- recogen prácticamente las tres fases del proceso artístico: latido emocional, flujo del sueño y maestría del invento. Los tres suelen ir asociados o próximos y caracterizan épocas como el romanticismo. Bajo tal consideración, M. Fernández resume en su poética el transcurso genético de la poesía.

La "función vocal" de "vivir soñando los inventos" está presente en toda su obra, tanto en fases sucesivas como en integraciones parciales de los tres ciclos en cada etapa de su escritura, con diferente resultado y constancia.

Aquí se integran los principales rasgos formales y postas semánticas de M. Fernández. A ellos se unirá, como derivación suya, el tema o función de la memoria, que centra, a su vez, otros aspectos colindantes.

Al intentar ceñir su obra prolija en el marco descrito, nos encontramos, no obstante, con una sorpresa. A pesar de la manifestación viva del sentimiento y del "tumulto" crítico de las palabras - los dos primeros ciclos reseñados-, la poesía de M. Fernández aparece desde el principio, en amplia medida, tamizada por un filtro de abstracción conceptual y lingüística, incluso cuando la referencia es clara o se mueve en un marco histórico, circunstanciado. No se trata de la vida en sí, plana, sino de "lo vivido". Tampoco es cuestión del sueño derramado, en consonancia surrealista, sino de "lo soñado", con arpegios musicales según acordes de fondo que estructuran el sonido. E incluso la viveza del sueño, su espontaneidad, es "lo vivo" en cuyo "envés" se fundamenta "lo inventado". La función poética de M. Fernández pasa por el pronombre lo. Abstrae la vivencia de base y la sitúa en un plano de realización acumulada, donde comienza el proceso narrativo. El poema será despliegue de una concreción conceptualizada, de un ángulo radiante de la conciencia. "Lo vivido" expondrá sus vivencias y resonancias: "lo soñado", el cauce del sueño; "Lo inventado", 
su trastienda, como una pulsación de aquellos acordes. En el lo se asienta la memoria y la narración. Son haz y envés de un mismo proceso. Al recordar, aunque sea lo remoto olvidado, narramos, y viceversa, pues en el relato exponemos la sucesión de los recuerdos y sus referencias. De ahí que la manifestación emotiva haya que entenderla más bien como un constructor de la mente y, la lingüística, como arquitectura del pensamiento. No se trata de la manifestación presencial de la conciencia en sentido fenomenológico, el momento mismo de su fluir, sino de un reducto suyo, ya calcáreo. El nivel narrativo establece, no obstante, un segundo orden simbólico-alegórico, según decíamos. El nivel de lo narrado sobrepasa el concepto abstraído, así como el lenguaje condensa su función instrumental en arquitrabes y frisos metafóricos. Dentro del significado conceptual inplicado en las palabras, la poesía de M. Fernández narra una sucesión de permutaciones metafóricas superpuestas, de lo que es reflejo suyo, en la sintaxis, la acumulación de sintagmas en maclas frásticas. Estamos ante una arquitectura metafórica. Sus estatutas y motivos remiten simbólicamente a otros niveles, con frecuencia a símbolos de símbolos, como puso de manifiesto Sultana Wahnón en un estudio sobre el irracionalismo de su obra (1). Entre metáfora y metáfora sí hay algunas veces, en algún verso o estrofa, constancia de la fluencia dimanante del pensamiento. Pero lo propio es que la metáfora encierre en sí, bien en el concepto, bien en el modo lingüístico, que es otra forma de conceptuar, una operación abstractiva, una aprehensión ya formalizada. En ese proceso, las sensaciones pierden parte de su halo expresivo y refuerzan la tensión de ese imán interno. Aunque cite referentes concretos, objetos comunes, el efecto de imanación abstractiva los diseca. Podríamos poner como ejemplo el poema contiguo al citado en Bóvedas, titulado "Juegos de magia". Incluye en él parte del campo semántico de un cobertizo y, a pesar de los nombres concretos, la impresión final de lectura es algo abstracto. El mismo poeta lo refleja así en los dos últimos versos. Después de quemar las concreciones, sus sensibles queda "tan huérfano" / que magia sólo es ya mi palabra", dice (2).

En esta "magia" hemos de ver aquel otro narrar "en la palabra" que antes comentábamos. La invención de aquí remite a ese campo gravitato- 
rio que las propias leyes del lenguaje determinan con su dinámica. Lo real actúa sólo en cuanto incarnado en formas lingüísticas, tal cual M. Fernández las siente y recrea. No hay otra manifestación, ni tumulto vocal, ni realidad inventada. Desde la sensación al concepto, desde la sílaba a la palabra, de ésta a la frase, todo remite hacia el imán de una fórmula subrepticia, la sintaxis oculta del vínculo conceptivo. Narrar ya resulta unir, conectar la presencia de una sintaxis formalizada, "la invención de estos mundos de la nada" (3), como dice el último verso del poema "El dormido". Es la nada del formalismo neomanierista sobre un fondo de meditación barroca.

El impulso inicial de M. Fernández, tumultuoso y onírico, se repliega en el último libro según sus propios fundamentos. La intranscendencia de una película narrativa.

En 1991 publica una antología de título sintomático, Fuegos de la memoria (4). Incluye en ella poemas primerizos de 1949 y 1950, publicados antes en revistas, y otros de libros ya conocidos, como Sagrada Materia (1966), Atentado Celeste (1975) y Monodia (1974). Los agrupa a tenor de un ambiente africano que hubiera sugerido parte de su obra como transición melillense entre ambos continentes. Muestran ya, en ciernes, gran parte de los rasgos formales y temáticos de su obra posterior.

En primer lugar resaltamos la arquitectura, el "invento" neobarroco y trabado de la prosa en el prólogo. El estilo de esas dos páginas condensa la escritura, tal vez contemporánea, de Historias de suicidas (1990) (5), si bien "Almazría" - así titula el prólogo- extrema aún más el efecto de estilo. Recuerda, por otra parte, la escritura de A. García López. Entre estos dos poetas hay similitudes estilísticas dignas de estudio y claramente diferenciadas respecto de otros autores coetáneos. Sería conveniente saber si opera en ambos un fondo retórico común, de tradición humanista y gusto por la forma arabesca, o si la entrañable amistad que los unía influye respectivamente en ambas escrituras. En tal sentido, es notable el uso del futuro e imperfecto de irrealidad y opción, asociado éste a un valor de pluscuamperfecto objetivo. La subjunción es forma de embellecimiento contemplativo de la realidad, bien como deseo, bien como mundo hipotéti- 
co donde lo real tuviera otra presencia, un plano de proyección comparativa, próximo a un juicio de valor estético. Anotamos asimismo la puntuación entrecortada de los períodos, la subordinación cadenciosa, con elevación de miembros suyos a oración autónoma, un léxico selecto, arcaizante en ocasiones, poético; anteposición de suplementos, determinativos; giro ampuloso y entrecortado de las cláusulas, con pausada y precisa colocación, central o final, del verbo; abundantes seriaciones, aposiciones y uso frecuente de netros con lo más participio o adjetivo, así como el pronombre quien con noción aforística, genérica e incluso gnómica.

En ese prólogo - almazría significa semillero- advertimos también una constante de su poética unida a aquel registro del uso metafórico-simbólico del segundo plano de realidad lingüística. Nos referimos al "pensamiento-comportamiento" que introduce una visión ética en el componente estético, una responsabilidad en la dimensión onírica, subjetiva, de lo real, porque la estética —así lo advierte M. Fernández- abre una vía al pathos de la conducta poética. Compara esta actitud con el "quietismo del religa$r e^{\text {} ~ o ~ c o n ~ u n a ~ e s p e c i e ~ d e ~ s u f i s m o . ~ L a ~ p a l a b r a ~ p o e ́ t i c a ~ g u a r d a ~ t a m b i e ́ n . ~}$ como la religión —así lo puso de manifiesto G. Santayana - una función unitiva con el mundo desgajado del origen por el distanciamiento, cada vez más progresivo de la abstracción respecto del contacto inicial con las cosas. Esta recuperación acaecida en el lenguaje poético también la puso de relieve el filósofo y lingüista gallego A. Ruibal. Es uno de los parámetros más importantes del romanticismo y simbolismo alemán, inglés y francés. Sin embargo, ya hemos visto que en M. Fernández esta religio actúa más bien en sentido contrario, hacia un nivel neutro de abstracción contemplativa, donde la inquietud de los sentidos, vivida como tal, encuentre aposento. Así interpretamos nosotros esa referencia suya al sufismo. Pero hay también en esta actitud un cierto neoplatismo, no en cuanto elevación del sensible a una idea proconcebida y omnímoda, pero sí en cuanto esencia o reducto de comprensibilidad hacia la que tiende todo orden sensitivo, dinámico, tal como entiende G. Santayana, este nivel. M. Fernández antecede la visión a la voz, el correlato analógico de la imagen visual a la fónica, aunque ésta va limando el perfil de las imágenes y, 
así, adquieren éstas también, como advierte hoy J. Derrida, una razón logocéntrica, o según Deleuze, una tangencia mutua de voz e imagen, los "lectosignes", que en M. Fernández formarían parte del "modulema", una variante aliterativa ya visible en algunos versos de 1949 , por ejemplo en:

"gozo del polen que rueda:

todo es un rendondel"

("El polen, Xauen").

Este fenómeno funciona a veces por elipsis barroca, visible en el ocultamiento de un referente que genera, traslapado, efectos suyos dimanantes. En el mismo poema antes citado, leemos:

"la miel es esto que va

dorando alas de insectos".

Además de abstracta, la metáfora recurre a una perífrasis. Al sol, el referente supuesto, lo sustituye un pronombre neutro, "esto", pero como si aquél estuviera presente en el gerundio "dorando" y en la imagen previa desplazada, del sustantivo "miel". La visión disemina el continuo de la voz en un perímetro fónico ambientador.

En otras alternativas, las cualidades sensibles se concretan objetivando lo abstracto, pero sin perder este valor. Citamos otros dos versos del mismo poema:
"Amarillo de los cálices
revientan venas de sed".

La no determinación de "amarillo" le confiere valor adjetivo sin referente sintagmático. La sustancia y el accidente coinciden en una sola palabra. Designa por sí sola todo el efecto colorista del sol germinando, como polen, en la naturaleza. Es realidad existencial. La abstracto acude en este caso a concretización de existencia y no al revés. 
La elipsis apositiva y atributiva concentra imágenes creando efectos de bella fluencia fónica, semántica y rítmica. Así, por ejemplo, en el poema titulado "Valle de las adelfas", de 1950:

"Su corazón de música en la altura

la voz amarga por tu tierra el viento".

Estos poemas están aún próximos al primer ciclo de la palabra, el emotivo. Sin embargo, hay alguna muestra de 1949 que correspondería al segundo, el de las voces tumultuosas. En ese año publica la revista Verbo un poema titulado "El odio", perteneciente a un libro inédito, Vigilia (6). Fue accésit, con otros cuatro, entre los que también figura A. Gamoneda, del premio convocado por esta revista, cuyo galardón correspondió a A. Figuera Aymerich. Se trata de un texto largo, de cuarenta y siete versos en su mayoría también dilatados, a modo de versículos, con tendencia al hemistiquio de siete, once y nueve sílabas, combinación que hará fortuna en libros posteriores, tanto suyos, como de otros poetas (7). Su tono recuerda el componente surrealista y la seriación galopante de P. Neruda y D. Alonso, pero también podría citarse a $G$. Celaya $-M$. Fernández comenta un libro suyo en otro número de la misma revista-, S. J. Perse o P. Claudel, al que se traduce en página de Verbo. Hay que anotar aquí las frecuentes alusiones de esta publicación al surrealismo y su impronta en España. Las reacciones son comedidas. Joan Fuster, por ejemplo, advierte que el componente irracionalista ya precedió a Bretón y su búsqueda de un "fonctionnement réel de la pensée". Para él se trata de una simulación, porque es imposible, dice, explorar el subconsciente en totalidad, por otra parte tan limitado como la conciencia misma, que también se muestra en sus dominios. Recuerda una observación de J. V. Foix a este propósito, según la cual la oceanografía del subconsciente sería aún más limitada que la razón. Joan Fuster iguala sus dimensiones (8).

Figura también en la portada de otro número, de 1948, una cita de A. Gide oportuna para nuestro caso. Dice: "La obra de arte sólo se obtiene mediante un esfuerzo y por la sumusión del realismo a la idea de la belleza 
preconcebida" (9). Es oportuna porque queda claro el tamiz apriorístico de la concepción en las orientaciones poéticas de la revista Verbo. Aunque no hay platonismo en Fernández, sí introduce a menudo una instancia apriorística, hipotética, con el modo subjuntivo y el condicional si. Es una hipótesis de irrealidad que funciona como premisa para enunciar una realidad, un posible como realidad alzada, buscada, como un futurible del pasado que se desvió fuera de los cauces intuibles o soñados. Equivale a un arquetipo.

Pero aún registramos más afinidades con los tres ciclos reseñados anteriormente. Otro número de 1948 inserta un fragmento de "Metafísica y poesía", de J. Wahl. Este pensador resalta la equivalencia de la invención artística y científica tras la superación de la idea cartesiana y newtoniana de la "localización simple", como hicieron Bergson, Withead y Heidegger. Poetas y científicos desarrollan maneras extrañas de pensamiento, es decir, no analógico-cartesianas. "Los rayos shelleyanos eran rayos cósmi$\cos ^{\prime \prime}$, añade $(10)$.

Si recopilamos lo expuesto, encontramos aquí el tumulto arpegiado de las voces, con el impulso vital debajo, y la invención de la "otra realidad" encarada al sueño en el envés de la moneda verbal. Todo ello bajo un tamiz de control y reducción abstractiva. J. Wahl señala también en el citado artículo que "los poetas proporcionan a los filósofos infinitos asuntos de meditación, y éstos pueden recordar — no es más que una frase de Descartes, joven todavía- que muchas veces hay más en el furor del poéta que en la sabiduría del filósofo" (11). De este tamiz quedan restos lógicos en la sintaxis de M. Fernández, por ejemplo en el poema "Plegaria Feijóo", del libro Discurso sobre el Páramo (12), así como en la sintaxis interna del engarce metafórico. Ahora bien, este libro incluye el método introyectivo en la persona de varias figuras históricas, como el P. Feijóo, Jovellanos, Goya mismo, etc. Es recurso frecuente de su obra, asociado al culturalismo, años antes de que idéntico fenómeno se pusiera de moda entre los "novísimos".

Un poema de 1981, incluido en Fuegos de la Memoria, nos sirve para exponer el cambio y avance operado en la poesía de M. Fernández respecto 
a los años cincuenta. Se titula precisamente "Llamando a la memoria" y resume parte de su indagación lírica a partir del libro Sagrada Materia (1967) El desarrollo de su estructura es disémico. Una piedra cae en una charca y se rompe la memoria con el consiguiente alboroto de imágenes, cuyas larvas se inquietan. En el plazo del recuerdo actúan a su vez otros dos, el oculto, soterrado en y aún antes de la infancia, como "goteo funerario", y la vigilia del "contemplar lo ayer vivido", que para M. Fernández es evidencia de una "orfandad". Este carácter de la memoria, pozo de misterios, pero sin raíz que la enmadre en algo concreto, huérfana, es reflejo de una muerte contínua, solapada, puntual, visible en la imagen del "goteo funerario". A partir de aquí, imágenes y palabras, aunque se encadenen unas en otras con transferencias sémicas o halos metafóricos, en realidad abisman un espacio insondable. M. Fernández trata de cubrirlo con reflejos epidérmicos de sintaxis cruzada.

En su escritura se nota un abatimiento de fondo, una anulación encubierta con voluntad neobarroca e incluso parnaisana de seres y objetos -aves, flores, nombres emblemáticos-, de cualidades —esplendores, destellos, aromas, "tactisignos"-, con lo que construye una sobrepiel o pergamino. Va escribiendo en él un diario lírico del desvanecimiento punteado por algún fulgor del paisaje y de la emoción amorosa. Así sucede en Discurso sobre el Páramo (1982), pero también en Tablas Lunares (1980), por ejemplo en el poema "El paso de las nubes" (13), donde la vida acusa una disminución entrópica desde la que inventamos, en tanto ausencia, un relleno de huecos. Del mismo modo funciona la historia en cuanto vacío perpetuamente relleno de vida interpretada e interpretándose. Esa piel se tensa o cuartea sin más resquicios que los conceptuales. Es piel-abrigo de la escritura, el halo epidérmico de la existencia. Al saberse perentoria en su mismo acto de conformación, la voz se transborda en película cutánea, en tejido de orfebrería. Refleja una muerte oculta, un suicidio lento, la obediencia impulsiva a "esta persistente ley solitaria / que erige sus dólmenes implacables", según dice en el poema "Elegía para un suicida", del libro Credo de Libertad (1958) (14). El verso queda así convertido en otra "antena" instintiva que comunica con el mundo: "Están cornunicando con 
el mundo / las enormes antenas del instinto", dice al comienzo del citado poema, dedicado a V. Aleixandre. Pero comunica más con sus reflejos "abstractos" - visuales, táctiles, sonoros, olfativos - que con sus impulsos abismados, sobre todo después de los seis primeros libros. La piel se conceptualiza cada vez más y las palabras se apoyan en la sombra seca de giros verbales abstractos. Hay quiebros bruscos entre períodos densos, con brillo de metáforas barrocas y manieristas. Con ello crea un túmulo envolvente, estatuario. La savia es recuerdo, memoria, con la vida, mientras la escritura avanza sobre losas dentadas. El referente se oculta y evade traslapado en reflejos distantes que vuelven críptico y hermético su lenguaje.

En alguna ocasión hablé con el propio M. Fernández de este fenómeno, así como de ciertas transiciones bruscas, no temperadas, en versos y estrofas. Según él, se trataba de un proceso de amnesia que, me dijo, le invadía a veces, sin pretenderlo, concluía en escritura, como llenando espacios lacunares. Habría que analizar esta observación a partir de los años 1975 y 1978, tal vez antes. Explicaría la impresión surrealista que producen algunos poemas suyos, pero este método de escritura sólo funciona aquí, como en otros poetas españoles contemporáneos, en cuanto referencia cultural. El automatismo y la metáfora surrealista se convirtieron a posteriori en recurso poético y en componente proyectivo, junto a otros, de la conciencia creadora. Perdió su aspecto de comportamiento vital - pretencía un modo concreto de vida- y retuvo la apropiación psicoanalística del desplazamiento, la ausencia. el Ersatz, el encubrimiento y sus espontáneos efluvios verbales. M. Fernández se refirió a este uso "de cierto automatismo a la hora de la creación" calificándolo de "leves rentas surrealistas" (15).

La amnesia no es, en principio, fundamento de irracionalidad, aunque sí de inconexión lógica aparente. Supone un esfuerzo de búsqueda a través del yermo de la memoria. La imagen irracional, en cambio, es una afluencia, un desbordamiento. Esto no impide que la amnesia desemboque también en efluvio verbal. Los dos casos presuponen una suspensión del orden lógico de las conexiones, pero uno busca la memoria perdida, de la que sólo tiene el hueco, y otro la vacía o recoge sus limos antecedentes, manifestando el hueco mismo. Falla la conexión del vínculo entre los compo- 
nentes del signo o la objetividad del referente, pero queda el halo del significante como principio de significación, o el halo semántico, el recubrimiento del significado, como principio significante. Nace el sentido a instancias de múltiples pulsiones parciales requeridas en ambos niveles lingüísticos, pero los significados no acuden en orden de vigilia social, sintagmática. Entonces se asocian referentes según imanación desplazada, incluida aquí también la imagen irracional, pero con ese recubrimiento de abstracción sensible o con la inminencia de "modulema", porque el significante se refugia en la dinámica procesual del lenguaje. El sentido crea un espacio corporal más extenso que el territorio semántico de las palabras o el conceptual de las ideas. Las palabras mismas son el sensible. Aún así, M. Fernández tamiza este proceso con un filtro lógico visible en marcas gramaticales de argumentación y exposición retórica, como señalamos en el aspecto narrativo de su poesía. Las precisiones, antes citadas, de la revista Verbo resultan sugerentes en este caso. M. Fernández es poeta atento al devenir de la reflexión lírica desde una impronta bastante acusada del discurso barroco. Este componente, más un "irracionalismo" amnésico, entreverado de conciencia verbal creadora, explican gran parte de su intención y alcance poético. 
1. WaHNóN, S., El irracionalismo en la poesía de Miguel Fernández, Antonio Ubago Editor, Cranada, 1983.

2. Fernández, M., Bóvedas, Ávila, Colección San Juan de la Cruz, 1992, p. 29.

3. Ibídem, p. 23.

4. FERNÁNDEZ, M., Fuegos de la memoria, Fondo de Cultura Andaluza, 1991.

5. FERNÁNDEZ, M., Historias de suicidas, Madrid, Ediciones Libertarias, 1990.

6. FERNÁNDEZ, M., "El odio", Verbo. Cuadernos Literarios, núm. 17, Nlicante, octubre-diciembre 1949 , p. 3.

7. El poema "Himno para el bosque de Bab-Chicar", entre los mejores suyos, del libro Fuegos de la Memoria, presenta esta misma inclinación métrica. Conf. pp. 87-89 de este libro, ya citado.

8. FUSTER, J., "El surrealismo y lo demás", Verbo, op. cit., julio-agosto 1948, pp. 10-11.
9. Verbo, op. cit., febrero 1948; en la portada.

10. Ibidem, juliu-agosto 1948, p. 2.

11. Ibidem.

12. FERNÁNDEZ, M., Discurso sobre el Páramo, Rusadir, Granada; 1982, p. 28. La estructura hipotética y causal explicativa queda clara en las expresiones "Si fuese", "sería", "pues", "ya que".

13. Fernández, M., Poesía completa (1958-1950), Madrid, Espasa-Calpe, 1983, p. 351 .

14. FERNÁNDEZ, M., Credo de libertad. Rusadir, Granada. 1979 , p. 46.

15. Gitado por LÓPEZZ GORJÉ, J., "Consideraciones en torno a Juicio final significativo poemario en la obra de Miguel Fernández”. Diario Melilla hoy, 20 de octubre de 1993, p. 12. 